\title{
Evaluation of Dermal Exposure to Polycyclic Aromatic Hydrocarbons in Fire Fighters
}

Kenneth W. Fent, PhD, CIH Judith Eisenberg, MD, MS

Doug Evans, PhD

Deborah Sammons

Shirley Robertson

Cindy Striley, $\mathrm{PhD}$ John Snawder, PhD Charles Mueller, MS Vance Kochenderfer Joachim Pleil, PhD Matthew Stiegel, PhD Gavin P. Horn, PhD

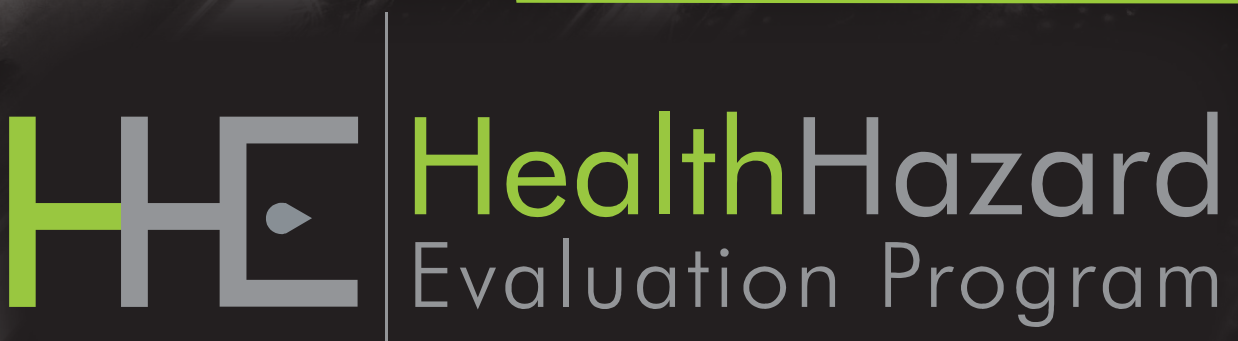

Report No. 2010-0156-3196 Summary December 2013

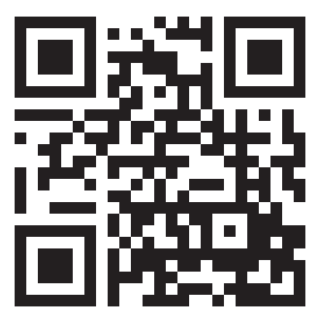

U.S. Department of Health and Human Services Centers for Disease Control and Prevention National Institute for Occupational Safety and Health

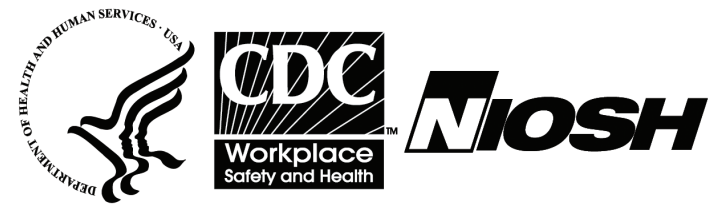




\section{Contents}

Introduction ....................................... 1

Methods ............................................ 1

Results and Discussion ....................... 1

Conclusions .......................................... 2

Recommendations............................. 3

The cover photo is a close-up image of sorbent tubes, which are used by the HHE Program to measure airborne exposures. This photo is an artistic representation that may not be related to this Health Hazard Evaluation. Photo by $\mathrm{NIOSH}$. 


\section{Introduction}

The Health Hazard Evaluation Program of the National Institute for Occupational Safety and Health (NIOSH) carried out a study of fire fighters' exposure to polycyclic aromatic hydrocarbons (PAHs) and other aromatic hydrocarbons during controlled structure burns. We wanted to know if these chemicals, which are produced during fires, pass through the skin and enter the fire fighters' bodies. Some PAHs and other aromatic hydrocarbons are known or suspected of causing cancer.

\section{Methods}

The study consisted of two rounds. In each round, five fire fighters fought a controlled structure burn once a day for 3 days. Fire fighters wore new or freshly laundered turnout gear each day and wore self-contained breathing apparatus (SCBA).

The burns took place in a timber-framed structure or a metal container; interior walls were covered with drywall. The rooms were set up with typical family room furniture. The burns lasted an average of 22 minutes. Fire fighters' activities included an average of 11 minutes watching the fire build, 3.5 minutes knocking down the fire, and 7.5 minutes doing overhaul. We collected air, breath, urine, and wipe samples of the skin (forearms, hands, neck, face, and scrotum) throughout the day. We analyzed the samples for the following:

- Levels of PAHs and aromatic hydrocarbons in the air during fire fighting

- Levels of PAHs on fire fighters' skin before and after firefighting

- Levels of PAHs and aromatic hydrocarbons in fire fighters' blood and urine before and after fire fighting

\section{Results and Discussion}

\section{PAHs and Aromatic Hydrocarbons in Air}

All the burns released PAHs into the air. The PAH levels in air during the burns were the same or higher than levels reported in other fire fighting studies. The levels of PAHs in air during active fires were higher than the occupational exposure limit for five of the burns. The air levels decreased after knockdown. However, for two burns, the air levels remained above the occupational exposure limit during overhaul. This is an important finding because fire fighters do not always wear SCBA during overhaul.

The equipment we used to measure aromatic hydrocarbons in air before knockdown only worked properly for one burn. During this burn, benzene was the main aromatic hydrocarbon in air, and was present at levels nearly 30 times the occupational exposure limit. The equipment we used to measure aromatic hydrocarbons in air after knockdown (during overhaul) worked properly for three burns. During these three burns, benzene, styrene, and toluene were the main aromatic hydrocarbons in air. They were present at levels well below occupational exposure limits. 


\section{PAHs on Skin}

The PAH levels on fire fighters' necks were higher just after fire fighting than just before. This finding suggests that the PAHs came from the fires. Fire fighters' necks were protected only by a Nomex ${ }^{\circledR}$ hood made of a double layer of porous fabric. Also, the hoods used in round 1 were shorter than those used in round 2, and some came untucked during firefighting. In general, we detected no PAHs on other areas of fire fighters' skin. The scrotum, forearms, and hands were protected by turnout gear or gloves made of multiple layers of protective fabric, and the face was protected by positive-pressure SCBA facemasks.

\section{PAHs in Fire Fighters' Bodies}

Levels of PAHs excreted in urine 3 hours after fire fighting were higher than those excreted just before or just after firefighting. However, the levels of PAHs in urine were similar to those found in workers with low levels of workplace exposures to PAHs. These findings suggest PAHs entered the fire fighters' bodies through their skin.

\section{Aromatic Hydrocarbons in Fire Fighters' Bodies}

Benzene was the main aromatic hydrocarbon we measured in fire fighters' breath. Levels of benzene in breath were higher just after fire fighting than just before. Other aromatic hydrocarbons (toluene, xylene, and styrene) also followed this trend. These findings suggest that aromatic hydrocarbons in air entered fire fighters' bodies through their skin. Because we detected no benzene in urine after fire fighting, it appears that the amount of benzene entering the fire fighters' bodies was low.

\section{Other Findings}

We tested the SCBA during round 2 on a breathing machine to make sure they were working properly. All but one SCBA passed the test. We found that turnout gear used during fire fighting became contaminated and released chemicals such as benzene into the air 25 minutes or more after fire fighting. Levels of the contaminants released from turnout gear were well below occupational exposure limits.

\section{Conclusions}

Benzene and some of the PAHs released during the controlled burns entered the fire fighters' bodies. Because fire fighters wore SCBA, the PAHs and benzene most likely entered through skin on the neck, which was the least protected area on the fire fighters' bodies. Benzene released from contaminated turnout gear may have been inhaled when fire fighters removed their gear after fire fighting. The levels of PAHs and benzene in fire fighters' bodies were similar to those in other groups of workers with low levels of workplace exposures to the same chemicals. Thus, turnout gear appears to protect skin against PAHs and aromatic hydrocarbons. 


\section{Recommendations}

On the basis of our findings, we recommend the following actions to further reduce exposure to PAHs and aromatic hydrocarbons during firefighting.

- To minimize breathing contaminants:

- Maintain and test SCBA routinely to ensure its proper function.

- Wear SCBA during overhaul.

- Remain upwind of the fire if not directly involved in the response.

- Provide as much natural ventilation as feasible to burned structures before starting investigations and when responders are not wearing respiratory protection.

- To minimize skin absorption of contaminants:

- Wear long hoods that are unlikely to come untucked during operations.

- Keep protective ensembles on during overhaul.

- Wash hands immediately and shower as soon as possible after a fire response.

- Put on laundered station uniforms after showering.

- Launder turnout gear routinely using a professional service.

- To minimize inhalation of chemicals that are released from contaminated gear:

- Remove SCBA (and hood) last when doffing gear.

- Doff gear before entering the rehab area.

- Store gear on the outside of the apparatus during the ride back to the station. 
This page left intentionally blank. 
The Health Hazard Evaluation Program investigates possible health hazards in the workplace under the authority of the Occupational Safety and Health Act of 1970 (29 U.S.C. § 669(a)(6)). The Health Hazard Evaluation Program also provides, upon request, technical assistance to federal, state, and local agencies to investigate occupational health hazards and to prevent occupational disease or injury. Regulations guiding the Program can be found in Title 42, Code of Federal Regulations, Part 85; Requests for Health Hazard Evaluations (42 CFR Part 85).

\section{Disclaimer}

The recommendations in this report are made on the basis of the findings at the workplace evaluated and may not be applicable to other workplaces.

Mention of any company or product in this report does not constitute endorsement by the National Institute for Occupational Safety and Health (NIOSH).

Citations to Web sites external to NIOSH do not constitute NIOSH endorsement of the sponsoring organizations or their programs or products. NIOSH is not responsible for the content of these Web sites. All Web addresses referenced in this document were accessible as of the publication date.

\section{Acknowledgments}

Analytical Support: Ardith Grote, Jennifer Roberts, Bureau Veritas North America, and NMS Labs Desktop Publishers: Mary Winfree

Editor: Ellen Galloway

Health Communicator: Stefanie Brown

Industrial Hygiene Field Assistance: Matthew Dahm, Gregory Burr, James Couch, Robert

McCleery, and Donald Booher

Logistics: Donnie Booher and Karl Feldmann

Respirator Inspection Support: Charles Wolfe

\section{Availability of Report}

Copies of this report have been sent to the employer, employees, and union at the call center. The state and local health department and the Occupational Safety and Health Administration Regional Office have also received a copy. This report is not copyrighted and may be freely reproduced.

This report is available at http://www.cdc.gov/niosh/hhe/reports/pdfs/2010-0156-3196.pdf.

\section{Recommended citation for this report:}

NIOSH [2013]. Health hazard evaluation report: evaluation of dermal exposure to polycyclic aromatic hydrocarbons in fire fighters. By Fent KW, Eisenberg J, Evans D, Sammons D, Robertson S, Striley C, Snawder J, Mueller C, Kochenderfer V, Pleil J*, Stiegel M*, Horn G†. Cincinnati, OH: U.S. Department of Health and Human Services, Centers for Disease Control and Prevention, National Institute for Occupational Safety and Health, NIOSH HETA Report No. 2010-0156-3196.

*U.S. Environmental Protection Agency, Human Exposure and Atmospheric Sciences Division +University of Illinois-Urbana/Champaign, Illinois Fire Service Institute 
Delivering on the Nation's promise:

Safety and health at work for all people through research and prevention

To receive NIOSH documents or more information about occupational safety and health topics, please contact NIOSH:

Telephone: 1-800-CDC-INFO (1-800-232-4636)

TTY: 1-888-232-6348

CDC INFO: www.cdc.gov/info

or visit the NIOSH Web site at www.cdc.gov/niosh

For a monthly update on news at $\mathrm{NIOSH}$, subscribe to NIOSH eNews by visiting www.cdc.gov/niosh/eNews. 